\title{
АНТИ-АПОЛОГЕТИЗМ И НАЧАЛО СОВРЕМЕННОЙ ИСТОРИОЛОГИИ ФИЛОСОФИИ
}

\author{
К.В. Райхерт
}

Современная история философии как отдельная философская дисциплина обязана своим возникновением немецкому философу и теологу Иоганну Якобу Брукеру ${ }^{1}(1696-1770)$, который в ряде своих работ предложил критический подход к изучению истории философии. Этот момент привлекает в последнее время все больше и больше внимания самих историков философии (см.: $[4,5,8,10])$ в связи с необходимостью прояснения эпистемических оснований истории философии как философской дисциплины.

Интерес современных историков философии к основаниям истории философии как философской дисциплины связан с принятым в современной эпистемологии разграничением практического и теоретического знания, то есть «знания-как» и «знания-что», в основе которого лежит мысль Л. Витгенштейна о том, что недостаточно доказать какое-то положение, необходимо еще показать, каким образом был проделан путь к этому положению [1]. Историков философии интересует то, как были получены основания истории философии как философской дисциплины, то есть историология философии. В контексте такого рода интереса с 1979 по 2004 год Институтом истории философии и Центром изучения средневековой философии Университета Падуи под руководством Джованни Сантинелло был, например, peализован проект «Storia delle storie generali della filosofia»(«История общей истории философии»): под таким названием выпущено 5 томов

\footnotetext{
${ }^{1}$ Французский философ Виктор Кузен (1792-1867) называет Иоганна Якоба Брукера «отцом истории философии» [6, с. 265].
} 
в 7 книгах (см.: [13-19]). С 1993 года в серии «nternational Archives of the History of Ideas» осуществляется английский перевод этого проекта под общим названием «Models of the History of Philosophy» («Модели истории философии») (см.: $[11,12])$.

Исследование, представленное в настоящей работе, посвящено влиянию возникшего во второй половине XVII века в рамках немецкой протестантской теологии движения анти-апологетизма ${ }^{2}$ на формирование современной историологии философии в XVIII веке. Выбор данной темы продиктован тем фактом, что И.Я. Брукер был причастен к этому движению.

Немецкая протестантская теология выступала против так называемой апологетической позиции, преобладавшей в римо-католической теологии. Данная позиция, апологетизм, исходила из идеи prisca theologia или philosophia perennis, согласно которой божественное откровение не было ограничено иудео-христианской традицией, а имело сознательных и несознательных представителей среди язычников. Понятие translatio sapientiae сделало возможным определенное мнение о том, что существует некоторое согласие между языческими традициями и христианством. Это позволяло учения таких мудрецов, как Зороастр, Гермес Трисмегист или Платон, рассматривать как содержащие элементы религиозной истины (см.: [9, с. 21-111]).

Однако против понятия translatio sapientiae выступил немецкий теолог и философ Якоб Томазий (1622-1684), один из учителей Г. Лейбница и предшественник современной историологии философии (см.: $[9$, с. 44]). Основным тезисом Я. Томазия, наиболее ясно разработанным в его сочинении «Schediasma historicum» («Сочинения историка», 1665), было следующее: христианство не было искажено в эпоху Возрождения, оно уже было искажено в первые столетия существования христианства языческими философами, для которых библейская вера была совершенно чуждой. Другими словами, Я. Томазий рассматривал так называемую «эллинизацию христианства» как некоторое извращение, поэтому он обосновывал необходимость разделения христианской теологии и философий языческих народов. По его мнению, христианская теология и языческая философия не имели ничего общего. Это означало, что любая идея, заимствованная у языческих философов, таких, как Платон или Аристотель, должна быть навсегда исключена из христианской теологии.

\footnotetext{
${ }^{2}$ Термин «анти-апологетизм» в обращение ввел современный немецкий историк 3. Леман-Браунз [9].
} 
Кроме того, наличие такого рода идей в христианской теологии свидетельствовало о том, что вся римо-католическая теология порочна и неприемлема. Я. Томазий ей противопоставляет протестантский идеал исключительного библейского благочестия (пиетета).

Я. Томазий показывает, что вся языческая философия восходит к учению Зороастра: именно Зороастр является источником платонизма, аристотелизма, эпикурейства и других античных философских учений. Сущностью этой языческой (зороастрийской) философии была вера в вечность миров, которая подразумевала одинаково «презренные» учения о дуализме, пантеизме и материализме, - все то, что полностью несовместимо с библейским creatio ex nihilo. Платоническая философия, средствами которой христианство больше всего пользуется, предполагает, в частности, учение об эманации. Согласно ему, душа свой источник имеет в вечной, божественной субстанции, в которую она возвращается после гибели тела. Этот «эманационизм» в свою очередь порождает учение об «энтузиазме», так как человеческие существа предположительно могут достичь знания (gnosis) своего божественного происхождения с помощью мистического прозрения. Возникшие в зороастризме, эти «пагубные» учения просочились в христианство частично в виде платонизма и стали сущностью платонико-христианского синкретизма сектантского движения, то есть римокатолического христианства. Логика протестантского анти-апологетизма Якоба Томазия, в конечном счете, привела к разграничению трех областей в истории мысли: (1) истории философии; (2) библейского откровения; (3) языческой религии.

Влияние анти-апологетизма Якоба Томазия можно обнаружить в работах таких немецких протестантских философов, как Фридрих Христиан Бехер, Балтазар Кипке, Иоганн Вильгельм Цирольд, Эрегот Даниэль Кольберг, Готфрид Арнольд, особенно же у сына Якоба Томазия - Христиана Томазия и Христофа Августа Хойманна. По сути, указанными философами на вооружение было взято предложенное Якобом Томазием различение истории философии и библейского откровения. В отличие от Якоба Томазия, который определял природу истинного христианства как несовместимую с любой языческой философией или религией, его сын, Христиан Томазий (1655-1728), использовал аргументацию отца, чтобы представить историю философии как автономную дисциплину. Христиан Томазий полагает, что нельзя в целом отбрасывать языческие философии, скорее нужно понять, чем они на самом деле являются, а именно: попыткой понять мир с помощью человеческих средств, без всякого божественного 
откровения.

Интерес Х. Томазия к истории философии обусловлен его идеей философии как средства преодоления традиционной академической культуры, берущей свое начало в аристотелевской философии. Х. Томазий описывает историю философии в своих книгах «Introductio ad philosophiam aulicam» («Введение в придворную философию», 1688) и «Cautelae Circa Praecognita Jurisprudentiae Ecclesiasticae» («Предостережения относительно предварительной церковной юриспруденции», 1712). История философии, по его мнению, выполняет чисто полемическую функцию, показывая пределы школьной философии и необходимость эклектического метода, единственно способного преодолеть традиционные подходы познания, такие, как картезианство и перипатетизм. Х. Томазий приписывает истории философии критическую роль: она должна демонстрировать «происхождение и прогресс ошибок, недостатков и ложной мудрости» [20, с. 58]. Историческое знание, в его понимании, такое же «око мудрости», что и философия, но независимое от нее:

Естественно, история - это об индивидуальных фактах, которые не представлены или уже имели место быть, в то время как философия отсылает к универсальному, на основании которого мы должны судить об истинности и благе других вещей [20, с. 57].

История и философия отталкиваются от чувств, однако история это знание о чувствах других, и поэтому она не может быть сведена к форме доказательного или научного знания, которое присуще философии. Таким образом, «историческое знание не является несомненным фактом, а скорее возможностью, которая предполагает акт „веры“, de fide historica» [20, с. 61]. По этой причине Х. Томазий рекомендует при изучении исторических дисциплин критическую осмотрительность, позицию сомнения. История философии является полезным предметом исследования. Она преследует две цели: (1) позволяет нам понять происхождение современных школ философии; (2) предупреждает нас от сектантства или догматизма. История философии представляет больший интерес для философов, но может быть полезной для юристов и теологов.

Точное определение истории философии Х. Томазий выводит из церковной истории:

История философии является историей происхождения и прогресса человеческой мудрости и глупости, отставляя в сторону божественное откровение. Отсюда следует, что история философии является в 
одном случае более полной, чем история Церкви, так как она показывает, помимо прочего, ошибки в натуральной философии и гражданском благоразумии, а в другом - необходимой частью церковной истории, так как она учит происхождению ложных догм, которые, притворяясь религией, навязываются обществу и государству, порождая беспорядок и несправедливость [20, с. 8].

История философии, с эклектизмом как моделью познания, становится наиболее удобным средством продвижения радикального обновления философской культуры, основанной на переоткрытии чувства единства и сотрудничества между философами:

Итак, вы можете спросить, не будет ли лучше иметь одну единственную и неизменную философию, чем отвратительную и изменчивую философию, собранную из кусочков, плохо подходящих друг к другу и постоянно разнящихся на протяжении времени. Недостаток этого заключается в слабости нашего ума и в сложности предмета, а не в философском методе. Нет никакой философии в действительности, уникальной и всегда верной самой по себе, которая бы заслуживала носить имя истинной философии, поэтому мы должны довольствоваться другой, эклектической философией [21, с. 45].

Подход Христиана Томазия произвел сильное впечатление на Христофа Августа Хойманна и его последователя Иоганна Якоба Брукера.

Христоф Август Хойманн (1681-1764) в работе «Einleitung zur historia philosophica» («Введение в историю философии», 1715) сообщает, что история философии, с точки зрения ее оснований, пытается дать обоснование практической природе, чтобы стать дисциплиной, годной для изучения, полезной наукой, в продвижении которой были бы заинтересованы все образованные люди. История философии может быть полезной в двух смыслах: общем и специальном. Общий смысл является тождественным для всех исследований истории, специальный смысл принадлежит истории философии. История является необходимым инструментом в различных областях обучения. Любая дисциплина, которая изучается адекватно, нуждается в понимании ее в контексте истории, показывающей ее происхождение и прогресс.

История оттачивает способность суждения с помощью «тренировки интеллекта», чтобы отличить истину от ошибки и чтобы отличить небылицу от истинной истории:

Обычным людям можно с легкостью позволить рассуждать таким способом: это написано, значит, это истинно. Но образованные люди не должны быть доверчивыми, а должны обладать критерием истинной истории и критерием небылицы как стандарта, по которому рассказы древних должны проверяться [7, с. 12]. 
История философии предлагает множество примеров неправдоподобных случаев: школа Пифагора представляет собой мешанину бесчисленных небылиц, как в принципе и жизни Фалеса и других древних философов. Таким образом, задача историка-способствовать продвижению более прочной и более критической культуры, готовой верить только в то, что исторически подтверждаемо или рационально правдоподобно.

Х.А.Хойманн полагает, что можно получить некоторую выгоду от истории философии. Прежде всего, история философии отрицает принцип авторитета, «который ослепляет большинство людей и заслоняет от них понимание истины» [7, с. 19]. Исследователь должен быть независим и свободен в своем познании истины. Философская точка зрения, которая гарантирует независимость и свободу мысли от авторитета, - это эклектизм, с которым история философии необходимо связана. Более того, эклектизм устраняет предрассудок авторитета и позволяет приобрести критическое мышление:

Мы узнаем из истории философии, что все философы-люди и что они могут ошибаться; поэтому глупо доверяться только одному философу и подчиняться его мнению. Липсиус ${ }^{3}$ хорошо сказал по этому поводу: «Школы возникли постепенно, что является обычной судьбой для мудрости, становящейся взрослее и, я бы сказал, немного безумнее». Таким образом, мы обнаруживаем, что эклектическая философия является лучшей формой философии в действительности, я бы сказал, что никто не заслуживает имени философа, если он не эклектик. Наоборот, любой, кто не занимается историей философии, оказывается в плену авторитета отдельного философа и, верно следуя за своим хозяином, например Аристотелем, более не способен увидеть свет. Он утверждает, что только Аристотель был мудр, и боится, что будет грехом противоречить ему в желании быть мудрее, чем тот есть $[7$, c. $20-21]$.

История философии является полезной отправной точкой для философского исследования, так как она представляет лучший метод для этого. Если бы картезианцы были большими экспертами в истории философии, они бы не занимались только вопросами природы, но и уделяли бы внимание моральной философии. В действительности, картезианство нуждается в сократовской реформе. Более того, пример Аристотеля убеждает нас в том, что нужно придавать большое значение логике. История философии ведет нас к пониманию текстов, на которых должно строиться наше познание.

\footnotetext{
${ }^{3}$ Юстус Липсиус (1547-1606) - бельгийский филолог-гуманист.
} 
Однако все эти результаты обусловлены способностью историка оценивать содержание и ценность различных основных положений должным образом; это требует философского ума и обучения и подразумевает, что историк философии должен быть философом:

Что ясно следует, так это-то, что никто, не будучи философом, не может обсуждать и преподавать историю философии правильно. Этот тип истории до сих пор имеет ряд недостатков, потому что большинство тех, кто писал по истории философии, такие как Фосс $^{4}$, $\mathrm{Xopн}^{5}$, Стэнли ${ }^{6}$, были скорее филологами, чем философами. Однако мы вправе разделять «историю философии» (historiam philosophiae) и «философскую историю» (historiam philosophicam). Но правильная «история философии» должна быть «философской», то есть должно рассматривать все с точки зрения его оснований, «истины фактов» и «истины догм». И критиковать общий предрассудок, что историкам не позволено выражать свое собственное суждение свободно, т.е. безосновательное мнение, которое Леклерк ${ }^{7}$ справедливо отверг [7, с. 34-35].

Различие между «историей философии» и «философской историей», которое возникло в полемическом сопоставлении в ранней историографии, служит для характеристики двух аспектов исторического исследования, которые должны быть интегрированы. Первый аспект выражает строго историческую точку зрения и относится к аккуратной и филологической реконструкции жизней и учений философов. Реконструкция такого рода впоследствии должна стать «философской» с помощью исследования оснований, которые поддерживают и демонстрируют истину как фактов, так и догм. Благодаря этому суждение историка становится «философски» обоснованным: оно сопоставляет ценность каждого учения с истиной, которая таким образом становится подлинным мерилом и различительным критерием философской историографии. В конечном счете, истинная история философии должна быть также «философской историей».

Чтобы четко отделить философию от всего того, что только ею кажется, Иоганн Якоб Брукер детально рассматривает все формы языческого синкретизма и показывает, что они основываются не на разуме, а скорее на предрассудках. Подход И.Я. Брукера представляет собой комбинацию протестантской библеистики и рациональной критики. Для него истина библейского откровения является предметом веры, которая не требует рационального обоснования. Однако помимо

\footnotetext{
${ }^{4}$ Герхард Иоганн Фосс (1577-1649) - нидерландский филолог.

${ }^{5}$ Георг Хорн $(1620-1670)$ - немецкий историк, географ и теолог.

${ }^{6}$ Томас Стэнли (1625-1678) - английский писатель и переводчик, автор популярной в XVII-XVIII веках книги «История философии».

${ }^{7}$ Жан Леклерк (1657-1736) - швейцарский теолог и библеист.
} 
нее существуют еще мнения языческих философов. По И.Я. Брукеру, история мысли есть история мнений; последние рассматриваются как «системы» мысли, которые могут быть описаны в рамках ограниченного числа предложений.

В своих работах «Kurze Fragen aus der philosophischen Historiae» («Краткие вопросы из истории философии», 1731-1736) [3] и «Historia Critica Philosophiae» («Критическая история философии», 1742-1744) [2] И.Я. Брукер делит философию на philosophia eclectica и philosophia sectaria. Philosophia sectaria в разное время была представлена халдейскими/зороастрийскими, египетскими системами, истинной древнегреческой философией, неоплатонизмом (античной эклектикой), каббалой, теософией. Указанные системы мысли основываются не на свете разума, а на слепой традиции, и выражаются в виде неясных образов и языка. Их системы сочетают основные ошибки всей ложной философии: атеизм, метафизический дуализм, отсутствие божественного провидения, доктрина эманационизма. Из всех указанных систем наибольшее доверие вызывает древнегреческая философия от Фалеса до Платона. После Платона древнегреческая философия и основанная на ней римская философия представляют собой набор предрассудков. В этом виноватым оказывается Платон, который соединил в своей философии элементы различных систем, например, пифагореизма и египетской системы. Для того чтобы преодолеть philosophia sectaria необходима philosophia eclectica, которая стала возможной только благодаря Реформации.

Мысль о том, что халдейская/зороастрийская и египетская системы мысли основываются на предрассудках, оказала неожиданный эффект на историков философии после И.Я. Брукера: так как было доказано, что указанные системы являются просто иррациональными предрассудками, то впредь не стоит их изучать в контексте настоящей философии. Это привело к тому, что в конце XVIII века появились работы, в которых история философии начиналась с Фалеса и Пифагора, а все, что было до этого, в том числе в других странах, например Египте, не рассматривалось. Наиболее показательными в этом смысле являются 6-томное сочинение Дитриха Тидемана (1748-1803) «Geist der spekulativen Philosophie» («Дух спекулятивной философии», 1791$1797)$ и 11-томное сочинение Вильгельма Готлиба Теннеманна (17611819) «Geschichte der Philosophie» («История философии», 1798-1819).

Как только все, что не относится к философии, было отброшено и стало предметом изучения истории теологии и истории эзотерики, историология философии приобрела современный вид. 


\section{Литература}

[1] Никоненко C.В. «Знание-как» и «знание-что» // Энциклопедия эпистемологии и философии науки. - М. : Канон+; РОИ Реабилитация, 2009. - С. 250-251.

[2] Brucker I.J. Historia critica philosophiae a mundi incunabulis ad nostram usque aetatem deducta, 6 Vols. - Lipsiae : Literis et Impensis Bern. Christoph Breitkopf, 1767.

[3] Brucker I.J. Kurze Fragen aus der philosophischen Historie, von Anfang der Welt biss auf die Geburt Christi, mit ausführlichen Anmerkungen erläutert, 7 Bd. - Ulm : Daniel Bartholomaei und Sohn, $1731-1736$.

[4] Catana L. The concept «System of Philosophy»: The case of Jacob Brucker's historiography of philosophy // History and Theory. 2005. - Vol. 44. - № 1. - P. 72-90.

[5] Catana L. The Historiographical Concept «System of Philosophy». Its Origin, Nature, Influence and Legitimacy. - Leiden: Brill, 2008.

[6] Cousin V. Cours de l'histoire de la philosophie moderne: École écossaise. - Vol. 1. - Paris, 1847.

[7] Heumann C.A. Einleitung zur historia philosophica// Acta philosophorum, das ist: Gründl. Nachrichten aus der historia philosophica, nebst beygefügten Urtheilen von denen dahin gehörigen alten und neuen Büchern. - 1715. - Bd. 1. - S. 1-62.

[8] Jacob Brucker (1696-1770): Philosoph und Historiker der europäischen Aufklärung. - Berlin: Auflage; Oldenbourg Akademieverlag, 1998.

[9] Lehmann-Brauns S. Weisheit in der Weltgeschichte. Philosophiegeschichte zwischen Barock und Aufklärung: Pt. 99 (Frühe Neuzeit). - Tübingen : Niemeyer, 2004.

[10] Lüdke C. Ich bitte mir Euer Hochedelgebohren Gedancken aus!: Beiträge zur Erschließung und Analyse von Jakob Bruckers Korrespondenz : Doctoral Thesis. - Universität Augsburg, 2006. 
[11] Models of the History of Philosophy. Vol.1. From its Origins in the Renaissance to the «Historia Philosophica». - Dordrecht : Kluwer Academic Publishing, 1993.

[12] Models of the History of Philosophy. Vol. 2. From Cartesian Age to Brucker. - Dordrecht: Springer, 2010.

[13] Storia delle storie generali della filosofia. Vol. 1. Dalle origini Rinascimenti alla «historia philosophica». - Brescia : La Scuola, 1981.

[14] Storia delle storie generali della filosofia. Vol. 2. Dall'età cartesiana a Brucker. - Brescia : La Scuola, 1979.

[15] Storia delle storie generali della filosofia. Vol. 3. Il secondo illuminismo e l'età kantiana. T. 1. - Padova: Antenore, 2000.

[16] Storia delle storie generali della filosofia. Vol. 3. Il secondo illuminismo e l'età kantiana. T. 2. - Padova: Antenore, 2000.

[17] Storia delle storie generali della filosofia. Vol.4. L'età hegeliana. T.1. La storiografia filosofica nell'area tedesca. - Padova: Antenore, 1995.

[18] Storia delle storie generali della filosofia. Vol.4. L'età hegeliana. T. 2. La storiografia filosofica nell'area neolatina e danubiana. - Padova: Antenore, 2004.

[19] Storia delle storie generali della filosofia. Vol.5. Il secondo Ottocento. - Padova : Antenore, 2004.

[20] Tomasius C. Cautelae Circa Praecognita Jurisprudentiae Ecclesiasticae: In Usum Auditorii Thomasiani. - Halae Magdeburgicae : Renger, 1712 .

[21] Tomasius $C$. Introductio ad philosophiam aulicam, sive lineae primae libri de prudentia cogitandi. - Lipsiae: Apud Autorem, 1688.

Надійшла до редакиї̈ 5 березня 2013 р. 